\title{
GMR
}

\section{DNA methylation profile of the $D K K 2$ gene as a biomarker in patients with colorectal cancer}

\author{
T.D. Silva ${ }^{1}$, A.V. Felipe ${ }^{1}$, V.M. Vidigal ${ }^{1}$, S.S. Saad ${ }^{2}$, N.M. Forones ${ }^{1}$ \\ ${ }^{1}$ Department of Medicine, Oncology Group, Gastroenterology Division, \\ Federal University of São Paulo, São Paulo, Brazil \\ ${ }^{2}$ Department of Surgery, Federal University of São Paulo, São Paulo, Brazil \\ Corresponding author: Tiago Donizetti Silva \\ E-mail: tiagodonizetti@outlook.com
}

Genet. Mol. Res. 16 (4): gmr16039816

Received September 1, 2017

Accepted September 28, 2017

Published October 14, 2017

DOI http://dx.doi.org/10.4238/gmr16039816

Copyright (C) 2017 The Authors. This is an open-access article distributed under the terms of the Creative Commons Attribution ShareAlike (CC BYSA) 4.0 License.

\begin{abstract}
Purpose: Epigenetic changes can be detected in precancerous lesions, suggesting that may be involved in the early stages of carcinogenesis. The methylation of specifics genes has been correlated with the outcome of many different types of cancers. This study compared the levels of DNA methylation between normal and tumor tissues from patients with colorectal cancer (CRC). Methods: Candidate genes were screened using the MethylProfiler $^{\mathrm{TM}}$ PCR Array System and the Dickkopf-related protein 2 (DKK2) genes were selected for study. DNA methylation of these genes was assessed by polymerase chain reaction-high-resolution melting (PCR-HRM) analysis. Results: Out of the 112 patients studied, 68 were controls with a mean age (SD) of 59.9 years (13.4) and 45 were patients with CRC with a mean age (SD) of 64.6 years (13.6). Among the patients with CRC, 25 were women, 28 were diagnosed with colon cancer and 18 were diagnosed with rectal cancer. The number of patients with Stage I, II, III, and IV of the disease, as per the TNM classification, were $2(4.3 \%), 20(43.4 \%), 18(39.1 \%)$, and $2(4.3 \%)$, respectively. Furthermore, the $D K K 2$ gene had a higher methylation profile in the CRC tissues when compared to normal mucosa $(\mathrm{p}<0.001)$, whereas the methylation profile
\end{abstract}


analysis was not statistically significant when comparing the stages of the disease $(p=0.078)$. Conclusion: The presence of differentially methylated sequences of the $D K K 2$ gene between the groups showed that the methylation changes of these genes could potentially be prognostic and predictive markers in CRC.

Key words: Biomarkers; Colorectal cancer; DNA methylation; Epigenetics; DKK2 gene

\section{INTRODUCTION}

Colorectal cancer (CRC) is the third most common cancer and the fourth leading cause of death from any cancer worldwide, accounting for a prevalence of approximately 1.4 million new cases and 700,000 deaths per year. The incidence is low in individuals younger than the age of 50, but does increase with age. The average age at diagnosis is approximately 70-years-old in developed countries (Arnold et al., 2017).

The number of new CRC cases in Brazil in 2016 (published by The Brazilian National Cancer Institute [INCA]) was 16,660 cases in men and 17,620 in women, corresponding to an estimated risk of 16 and 17 new cases per 100,000 men or women, respectively (INCA 2017).

Colorectal cancer results from the accumulation of multiple alterations in the (epi) genome of the large intestinal epithelial cells. In 1990, Fearon \& Vogelstein proposed a model for colorectal carcinogenesis, where the accumulation of alterations in multiple genes that regulate cell growth and differentiation, including tumor suppressor genes and oncogenes, leads to the initiation and progression of cancer. Both epigenetic and genetic changes modify these key genes involved in carcinogenesis (Fearon and Vogelstein (1990).

CRC develops through three distinct pathways: chromosomal instability (CIN), microsatellite instability (MSI), and the $\mathrm{CpG}$ island methylator phenotype (CIMP). In recent years, it has been established that other systems and pathways are involved in the pathogenesis of colorectal cancer, including abnormal DNA methylation, inflammation, and, more recently, the discovery that microRNAs (miRNAs) can actively contribute to the process of carcinogenesis (Colussi et al., 2013).

The term "epigenetics" was coined half a century ago by combining the words "epigenesist" and "gene" to describe the mechanisms of cell design and lineage specification during the development of animals (Holliday, 1990; Waddington, 1959). Today, this term is generally used to describe those mechanisms able to modify the expression levels of selected genes without necessarily altering their DNA sequence. Epigenetic modifications may vary for each cell type, acting in various ways to regulate gene expression through the organization of the nuclear architecture of chromosomes, restricting or facilitating access to DNA transcription factors, as well as preserving the memory of transcriptional activity (Duthie, 2011).

Epigenetic modifications are often induced environmentally and are tissue-specific phenomena that can have similar effects to those of pathogenic mutations or functional polymorphisms, with the ability to silence, upregulate, or down-regulate the expression of a selected gene in each tissue. This has relevance in carcinogenesis where cancer-related genes, such as tumor suppressor genes or DNA repair genes, are involved (Bernstein, 2011).

DNA methylation is one of the most common epigenetic modifications. It occurs in mammalians at CpG dinucleotides via the addition of a methyl group at the 5' position of cytosine to form a 5-methylcytosine. These chemical changes occur preferentially in regions called $\mathrm{CpG}$ islands, which are long repeated sequences of cytosines next to a guanine nucleotide. Methylation of $\mathrm{CpG}$ islands within the promoter region of a gene can cause transcriptional repression of the gene involved and has been correlated to the outcome of different types of cancers (Gonzalo et al., 2010).

As methylation marks are removed from genomic DNA by DNA polymerases and are not replicated in vitro by PCR amplification, it is necessary to chemically modify the DNA template with sodium bisulfite to preserve methylation information before PCR amplification. In the 1990s, Frommer et al. developed a procedure using sodium bisulfite to distinguish 5-methylcytosine from cytosine in the DNA. The authors used sodium bisulfite to deaminate genomic DNA, in which the unmethylated cytosine is converted to uracil, while 5-methylcytosines 
remain unchanged. Thus, it is possible to distinguish between methylated and unmethylated DNA, since the presence of cytosine after treatment indicates a methylated sequence (Frommer, 1992).

Pyrosequencing of sodium bisulfite-treated DNA is considered the gold standard procedure for studying DNA methylation; however, comparative studies using PCR-HRM are more cost-effective and highly accurate for the detection of methylated products (Migheli et al., 2013).

PCR-HRM is performed using PCR-amplified double-stranded DNA in the presence of a DNA intercalating dye, which emits fluorescence when bound to double-stranded DNA. The melting temperature is defined as the specific temperature at which the DNA helix dissociates into two single strands and a sharp drop in the fluorescence is observed. Each PCR product has a distinct melting temperature dependent on the DNA sequence and the changes in fluorescence levels across a denaturing gradient describe an amplicon's melting profile (Wojdacz et al., 2009).

Curative treatment is possible in $90 \%$ of CRC cases when diagnosed at an early stage (Toribara and Sleisenger, 1995). Screening programs for early detection of CRC and polyps reduces the incidence and mortality rates (Winawer, 2007; Pignone and Lewis, 2009), and may be cost-effective (Lansdorp-Vogelaar, 2011). Although, the current non-invasive screening procedures for CRC are ineffective. The fecal occult blood test (FOBT) is widely used and reduces mortality rates by up to $20 \%$ when performed every 2 years (Atkin, 2013). However, this method has low sensitivity for detection of early tumors and precancerous lesions (Imperiale et al., 2004). There is increasing evidence that the fecal immunochemical test (FIT) for hemoglobin level offers several advantages over traditional guaiac FOBTs (Arnold et al., 2017).

The determination of epigenetic events in DNA can be a strong candidate for non-invasive methods for the early detection of the disease, since the regulation of gene expression by aberrant DNA methylation is well characterized in tumor biology and widely described for the carcinogenesis of CRC. Several genes may be methylated and may be candidates for further research.

\section{MATERIALS AND METHODS}

A case-controlled study was conducted including 45 patients with primary CRC admitted to the University Hospital of the Federal University of São Paulo (UNIFESP) for surgical resection of tumors, and 68 control patients with normal colonoscopy without prior diagnosis of malignant disease.

Samples of tumor tissue from CRC patients were removed by the surgical pathologist and immediately frozen in liquid nitrogen. Normal colon biopsy specimens were collected from patients in the control group during colonoscopy and stored in Allprotect ${ }^{\circledR}$ (QIAGEN, Hilden, Germany). The study was approved by the ethical committee of the UNIFESP and all patients gave informed consent. Patients with inflammatory bowel disease and a history of hereditary cancer (Lynch syndrome or polyposis adenomatous familiar), chemotherapy or radiotherapy, or other types of cancer were excluded.

\section{Extraction of DNA}

DNA samples were extracted using commercial kits according to the manufacturer's instructions. For surgical tumor tissues, $25 \mathrm{mg}$ of fresh frozen tissues were cut into small pieces and incubated for $6 \mathrm{~h}$ at $56^{\circ} \mathrm{C}$ using a QIAamp® DNA Mini Kit (QIAGEN). After every $30 \mathrm{~min}$ of incubation, the tissue was vortexed to assist lysis. The DNA was eluted in nuclease-free $\mathrm{H}_{2} \mathrm{O}$ and stored at $-20^{\circ} \mathrm{C}$.

DNA from colonoscopy biopsies, no larger than $10 \mathrm{mg}$ in size, was extracted using the QIAamp® DNA Micro Kit (QIAGEN). Sterile gauze was initially used to remove excess Allprotect ${ }^{\circledR}$. The biopsy fragments were incubated overnight at $56^{\circ} \mathrm{C}$. During incubation, the tissue was vortexed to aid lysis. The DNA was eluted in nuclease-free $\mathrm{H}_{2} \mathrm{O}$ and stored at $-20^{\circ} \mathrm{C}$. The DNA extracted from tissue was quantified using a NanoDrop® spectrophotometer and QUBIT® 2.0 (Invitrogen).

\section{Treatment of DNA with sodium bisulfite}

The DNA was treated with bisulfite using a Cells-to-CpG ${ }^{\mathrm{TM}}$ Bisulfite Conversion Kit Reagents ${ }^{\circledR}$ (Applied Biosystems $\left.{ }^{\circledR}\right)$, according to the manufacturer's instructions. For bisulfite treatment of genomic DNA, 50-1500 $\mathrm{ng} / \mu \mathrm{L}$ DNA was treated in a final volume of $45 \mu \mathrm{L}$. 
After treatment with sodium bisulfite, the DNA was quantified by spectrophotometer to verify the quality of the treatment and stored at $-20^{\circ} \mathrm{C}$.

\section{Selection of primers}

The primers for the DKK2 gene was designed using Methyl Primer Express® v1.0 and Primer Express ${ }^{\circledR}$ v3.0.1 by the MSP (Methylation Sensitive Primer) where two pairs of primers are synthesized for each gene, one for amplification of the methylated DNA and other for the unmethylated DNA (Table 1).

\begin{tabular}{|c|c|c|c|c|}
\hline Genes & Sequences & $\begin{array}{l}\text { Temperature of } \\
\text { annealing }\end{array}$ & Primer concentration & $\begin{array}{c}\text { CpGs } \\
\text { number/ } \\
\text { amplicon } \\
\text { size }\end{array}$ \\
\hline$D K K 2 \mathrm{HM}$ - forward & AGGTATCGTTGCGTTGGTAGC & $63^{\circ} \mathrm{C}$ & $10 \mathrm{pmol}$ & $3 ; 139$ \\
\hline$D K K 2 \mathrm{HM}$ - reverse & AAATCAAAAAACGTCCCCGA & & $10 \mathrm{pmol}$ & \\
\hline$D K K 2 \mathrm{UM}$ - forward & TTTAGGTATTGTTGTGTTGGTAGT & & $10 \mathrm{pmol}$ & $0 ; 139$ \\
\hline$D K K 2 \mathrm{UM}$ - reverse & AAATCAAAAAACATCCCCAAACC & & $10 \mathrm{pmol}$ & \\
\hline
\end{tabular}

\section{Analyzing the methylated DNA by high-resolution melting}

The qPCR reaction and subsequent analysis by high-resolution melting (PCR-HRM) were performed sequentially in an ABI@StepOnePlus thermocycler (Applied Biosystems®).

PCRs were performed in a final volume of $25 \mu \mathrm{L}$ (standardized to multiplex) containing in total: $12.5 \mu \mathrm{L}$ MeltDoctor Master Mix ${ }^{\mathrm{TM}}$ HRM (Applied Biosystems ${ }^{\circledR}$ ), primers (forward and reverse), and 10-20 ng of DNA treated with bisulfite (at a concentration of $20 \mathrm{ng} / \mu \mathrm{L}$ ). Cycle times were one cycle of $15 \mathrm{~min}$ at $95^{\circ} \mathrm{C}$, followed by 60 cycles of $15 \mathrm{~s}$ at $95^{\circ} \mathrm{C}, 30 \mathrm{~s}$ at the annealing temperature of the primers (Ta), and $30 \mathrm{~s}$ at $72^{\circ} \mathrm{C}$. PCR-HRM was performed by setting the melting temperature of the fluorescence emission to that recommended by the manufacturer, $70-95^{\circ} \mathrm{C}$, in increments of $0.1^{\circ} \mathrm{C} / 2 \mathrm{~s}$. Assays were performed in duplicate.

A control for fully methylated DNA and unmethylated DNA was included (methylated and unmethylated EpiTect@ human control DNA, bisulfite converted) (Qiagen, Milan, Italy), and titrated to obtain the following standard curve: $0 \%, 12.5 \%, 25 \%, 50 \%, 75 \%$, and 100\%. The standard curve, with known methylation levels, was included in all experiments where it was used to determine the methylation levels of tumor and control samples.

\section{Data analysis was carried out using HRM Software v3.0.1 (Applied Biosystems@).}

To determine the methylation profile, the analysis method developed by Migheli et al. was used (Migheli et al., 2013). For this analysis, melting curve graphs of the standards were generated at various temperatures and were represented by relative fluorescence units (RFUs). In each experiment, five RFUs for each point of the curve $(0 \%, 12.5 \%, 25 \%, 50 \%, 75 \%$, and $100 \%)$ were averaged and a linear regression curve generated.

A linear regression function of the Minitab software program was used for analysis, which generates similar results to those derived by Lagrange interpolation. The RFU for each sample was compared with the linear regression curve of the standards in each experiment to determine a percentage methylation for the gene of interest.

\section{STATISTICAL ANALYSIS}

The optimal cut-off methylation index for the genes was calculated by a receiver operating characteristic (ROC) curve. The sensitivity, specificity, and accuracy of each gene were measured from this cut-off value.

For the linear regression curve of standards in each experiment, the RFU for each sample produced a precise percent methylation. 
For patients in the CRC group the tumor sites were compared to the rate of methylation. The ANOVA test was used for these analyses.

SPSS V16, Minitab 15 and Office Excel 2016 software packages were used. A p value <0.05 was considered statistically significant.

\section{RESULTS}

Clinical characteristics of patients in the control and CRC groups are described in Table 2. Of the 45 CRC patients, 25 were women with a mean (SD) age of 63.3 (12.8) years. Of the 68 control patients, 42 were women with a mean age of 59.9 (14.8) years. In the CRC group, 28 (62.2\%) and 17 (37.8\%) patients were diagnosed with colon and rectal cancer, respectively. The disease stage of the CRC patients according to the TNM classification system were as follows: 2 patients (2.2\%) were stage I, 20 (44.4\%) were stage II, $18(40.0 \%)$ were stage III, and 2 (4 4\%) were stage IV; the pathological stage of 4 patients could not be accessed (Table 2).

Table 2. Characteristics of the patients.

\begin{tabular}{|c|c|c|c|c|}
\hline & Patients & & Control & $p$ \\
\hline Parameters & $\mathrm{N}(\%)$ & & $\mathrm{N}(\%)$ & value \\
\hline Age ( \pm DP) & & $63.3(12.8)$ & $59.9(14.8)$ & $0.96^{\mathrm{a}}$ \\
\hline$\leq 50$ years & & $5(11.2)$ & $16(23.5)$ & $0.196^{b}$ \\
\hline$>50$ years & 40 & $(88.8)$ & $52(76.5)$ & \\
\hline \multicolumn{5}{|l|}{ Gender } \\
\hline Male & 20 & (44.4) & $26(38.2)$ & $0.292^{b}$ \\
\hline Female & 25 & (55.6) & $42(61.8)$ & \\
\hline \multicolumn{5}{|l|}{ Tumor site } \\
\hline Colon & 28 & $(62.2)$ & & \\
\hline Rectum & 17 & (37.8) & & \\
\hline \multicolumn{5}{|l|}{ Stage } \\
\hline I & 2 & $(2.2)$ & & \\
\hline II & 20 & (44.4) & & \\
\hline III & 18 & $(40.0)$ & & \\
\hline IV & 2 & (4.4) & & \\
\hline NI & 4 & (8.9) & & \\
\hline est; b $\chi^{2}$ test; & & & & \\
\hline
\end{tabular}

The methylation profiles were divided into three subgroups, namely: <0\%, unmethylated (UM); 1-25\%, methylated (M); > 25\%, hypermethylated (HM).

Reference values and RFUs of each gene/plate were used to create linear regression models and define a model that can predict the rate of methylation, with the explanatory value of the RFU. Samples were grouped according to the methylation profile and compared among the groups. The DKK2 gene showed the most frequent methylation profiles in the CRC group (84.7\%; $\mathrm{p}<0.001)$ (Table 3). 
Table 3. Methylation profile of genes of tissue.

\begin{tabular}{|c|c|c|c|c|c|c|}
\hline \multirow[t]{2}{*}{ Variables } & & \multicolumn{2}{|c|}{ CRC } & \multicolumn{2}{|c|}{ Control } & \multirow[t]{2}{*}{$P$} \\
\hline & & $\mathbf{N}$ & $\%$ & $\mathbf{N}$ & $\%$ & \\
\hline & Unmethylated & 7 & 15.2 & 60 & 11 & $<0.001$ \\
\hline \multirow[t]{2}{*}{$D K K 2$} & Methylated & 10 & 21.7 & 3 & 88.2 & 0.004 \\
\hline & Hypermethylate & 29 & 63.0 & 5 & 4.4 & $<0.001$ \\
\hline
\end{tabular}

*Test for equality of two proportions

A comparison of the TNM stage with the gene methylation profile of DKK2 gene indicated that the methylation profile of the genes did not significantly differ between stages II and III ( $\mathrm{p}=0.106$ respectively).

Patients with a lack of clinical information or stage I or IV tumors (because of the small sample size, i.e., one and two cases, respectively) were excluded from the analysis. The methylation profile showed no difference in relation to the stage of the disease $(\mathrm{p}=0.078)$.

The ROC curve was generated to determine the optimal cut-off methylation index for diagnosis of CRC. The DKK2 gene had the optimum ROC curve, with an area under the curve of 0.937 . The cut-off methylation index was $-4.1 \%$ with a sensitivity of $89.1 \%$ and specificity of $86.8 \%$ (Figure 1 and Table 4 ).

Table 4. Sensitivity, specificity, and accuracy of $D K K 2$ gene. 


\section{ROC Curve}

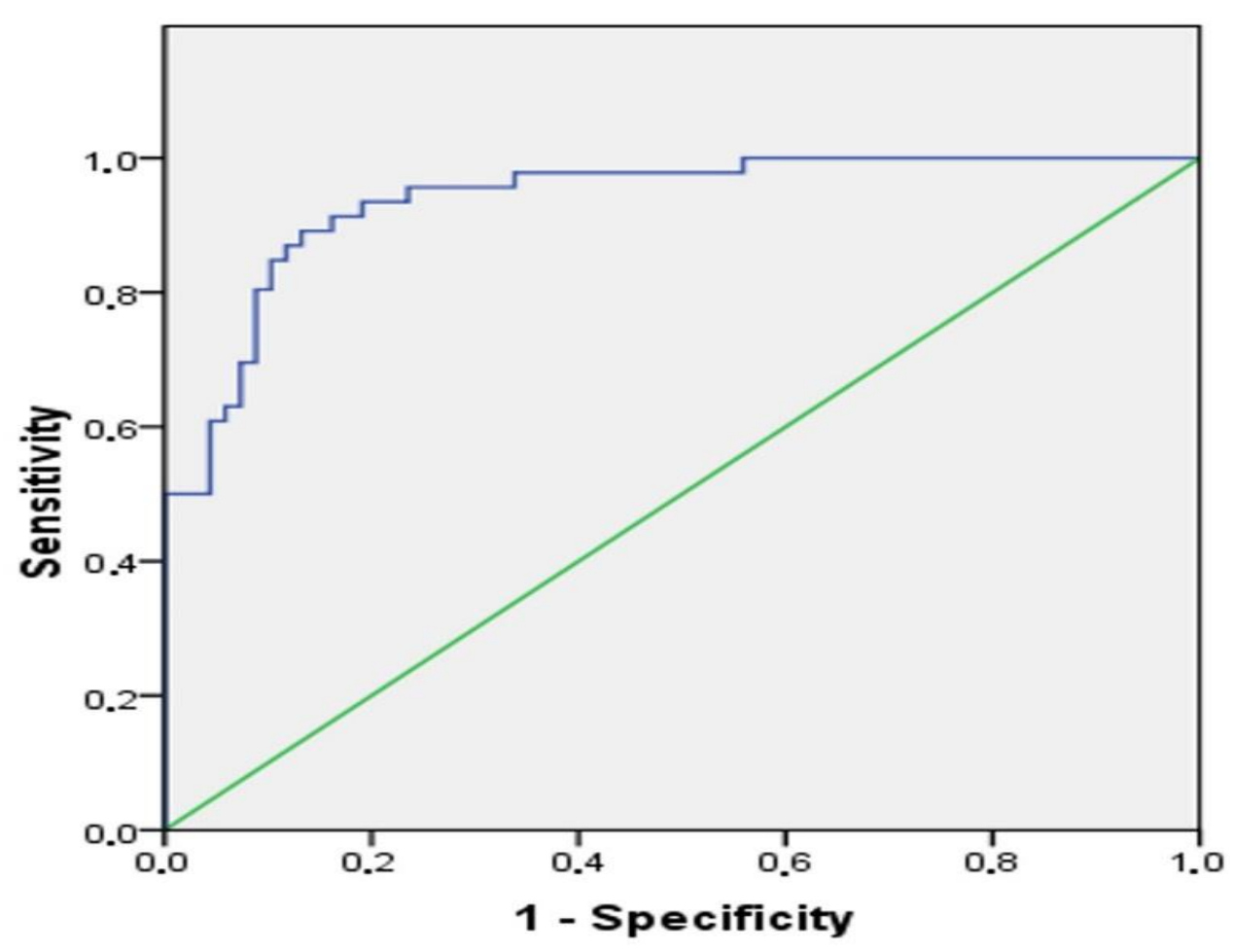

Figure 1. ROC curve.

\section{DISCUSSION}

The global burden of CRC is expected to increase by $60 \%$ to more than 2.2 million new cases and 1.1 million cancer-related deaths by 2030 . In the United States, there are projected to be 135,430 individuals newly diagnosed with CRC and 50,260 deaths from the disease in 2017. Although, the majority of these new cases $(58 \%)$ occur in people aged 65 years or older (Siegel, 2017).

In our study, of the 45 patients with CRC, $55.6 \%$ were women, the average age was 63.3 years, and most patients were over the age of $50(88.8 \%)$. These data are consistent with those in publications by INCA, which describes the incidence of CRC as 52.6\% in women and as $47.3 \%$ in men (INCA, 2017).

Patients were subdivided by their tumor site (i.e., colon or rectum), where $28(62.2 \%)$ patients had tumors in the colon and $17(37.8 \%)$ in the rectum.

Methylation plays an important role in regulation of this pathway and many genes have altered methylation patterns in the tumor compared to genes in the normal colon mucosa (Colussi et al., 2013). Therefore, the analysis of the melting profile can determine the level of methylation in each sample (Tachibana, 1981). Once DNA is treated with sodium bisulfite, the PCR products derived from an unmethylated template will have a lower melting point than those derived from a methylated template.

In a study carried out by our laboratory, 24 genes were analyzed using Methyl Profiler ${ }^{\mathrm{TM}}$ DNA Methylation Polymerase Chain Reaction (PCR) Array System (SA Biosciences, Hilden, Germany). The difference in the methylation profile of the genes between the groups was evaluated to identify the genes with the greatest potential to differentiate a healthy tissue from a cancerous tissue (Table 5). 
Table 5. Profile methylation screening.

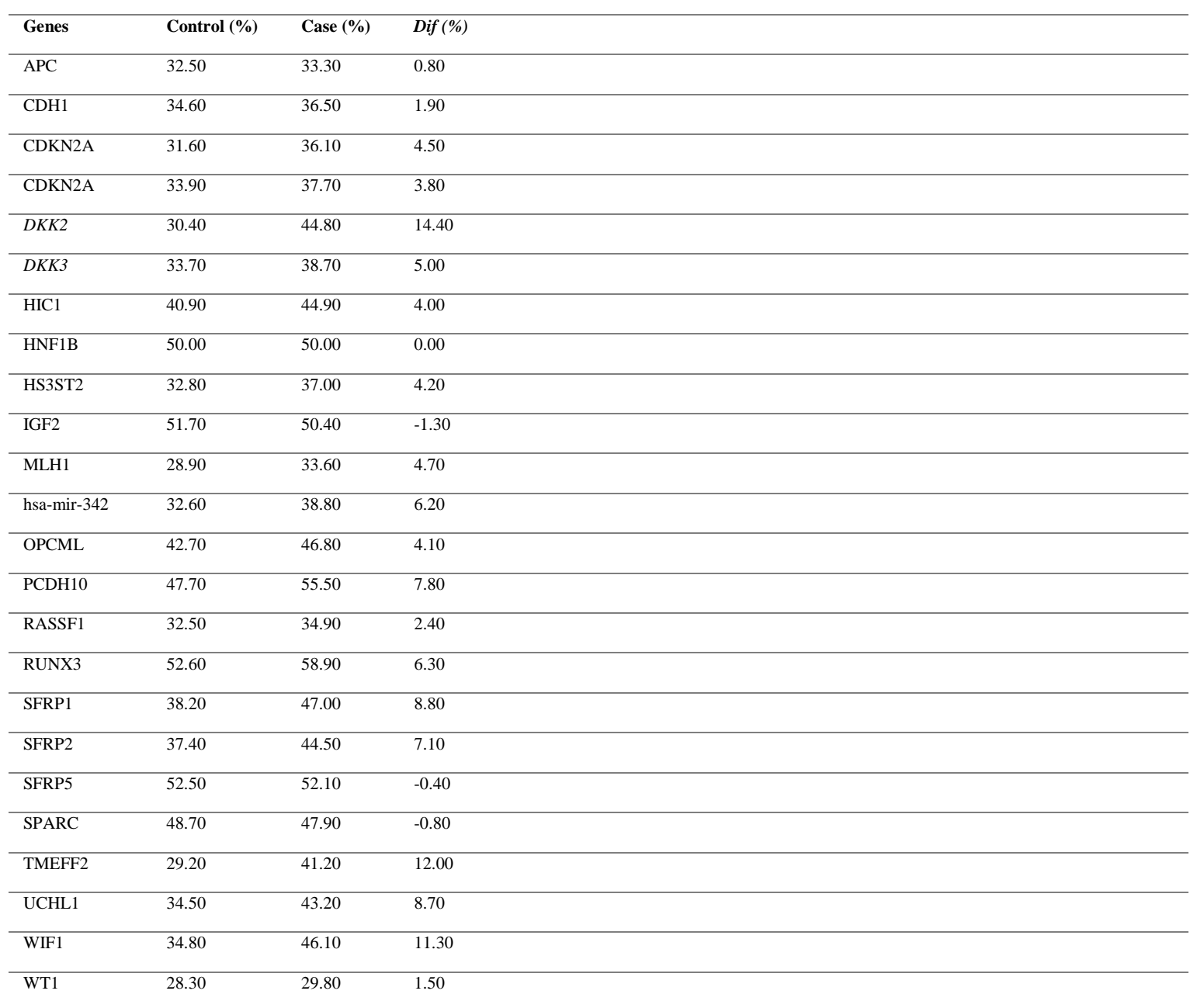

A total of three genes were identified that may be potential epigenetic markers for CRC screening. The three genes that presented the greatest increase $(>10 \%)$ of the methylation percentage in the cancerous tissue in relation to the healthy mucosa was DKK2 (14\%), TMEFF2 (12\%), and WIF1 (11.3\%) (Figure 2). Of these three genes, $D K K 2$ was an extracellular Wnt antagonist, WIF1 was a tumor suppressor gene, and TMEFF2 has been shown to function as both an oncogene and as a tumor suppressor gene depending on the cellular context (Silva et al., 2013). In this study, we evaluated the DNA methylation of the DKK2 gene as a function of the importance of the Wnt signaling pathway in CRC carcinogenesis. 


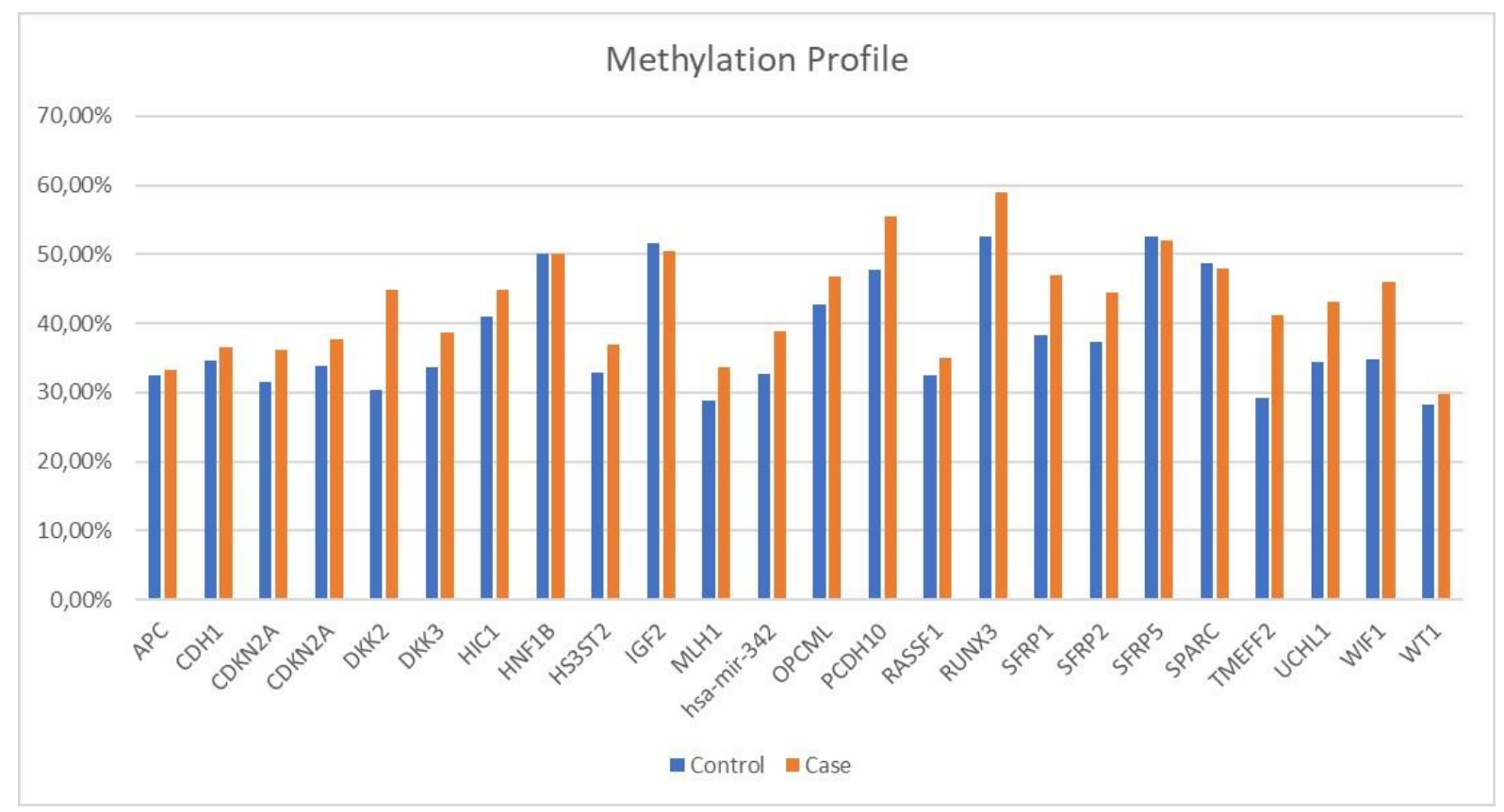

Figure 2. Methylation profile.

Of the four vertebrates Dickkopf-related (DKK) proteins (DKK1, DKK2, DKK3, and DKK4), DKK1 and DKK2 are secreted proteins with two cysteine-rich domains separated by a linker region. During vertebrate development, the DKKs are involved in the formation of the head and limbs, in osteoblast differentiation, and in ocular formation. $D K K 3$ and $D K K 4$ proteins also have a cysteine-rich domain. DKK1, DKK2, and DKK4 function as antagonists of the canonical Wnt signaling pathway by binding to LRP5/6 and thereby preventing the interaction between LRP5/6 and the Wnt complex. The DKKs 1, 2, and 4 can also bind to the cell surface protein Kremen-1 or -2, promoting the internalization of LRP5/6. Unlike members of the DKK family that bind to the Wnt co-receptor, $D K K 3$ appears to inhibit Wnt/ $\beta$-catenin signaling by preventing its nuclear translocation (Zhu et al., 2012). DKK1 targets $\beta$-catenin and has been reported to be epigenetically inactivated in CRC. DKK3 is also negatively regulated in various cancers, such as osteosarcoma, hepatocellular carcinoma, and prostate cancer (Hirata et al., 2009). DKK2 is a putative inhibitor of Wnt signaling that is generally down-regulated in human cancers, including renal cell carcinoma, melanoma, and gastrointestinal tumors. However, it has remarkable functions as a tumor suppressor molecule and, in contrast to other members of the DKK family, $D K K 2$ can function as an agonist or antagonist of LRP5/6. Furthermore, DKK2 can functionally switch from an activator to an inhibitor of Wnt/LRP6, providing a mechanism for regulation of Wnt activity. Conflicting studies have reported DKK2 gene up-regulation in several human cancers, including CRC (Zhu et al., 2012).

In cell culture studies, $D K K 2, D K K 3$, and $D K K 4$ were silenced by DNA methylation more often than DKK1. An inverse relationship between the expression and methylation was seen in all cases except $D K K 4$, proving that DKKs are silenced by DNA methylation (Voorham et al., 2013).

Recent studies have reported that $D K K 2$ is epigenetically inactivated in numerous types of cancers and that its gene products exhibit tumor-suppressive properties. Wang et al. examined the expression of $D K K 2$ in colon tumor cell lines, as well as its promoter methylation status in colon tumor cell lines and primary tumors (Wang et al., 2017). They showed that the down-regulation or silencing of $D K K 2$ was closely associated with the hypermethylation status of its promoter. Furthermore, $D K K 2$ expression could be restored by a demethylation treatment, resulting in the down-regulation of active $\beta$-catenin and its downstream target genes. They concluded that $D K K 2$ appears to be a functional tumor suppressor gene regulating tumorigenesis of colorectal cancer by antagonizing the $\mathrm{Wnt} / \beta$-catenin signaling pathway (Wang et al., 2017).

Sugai et al. quantified the DNA methylation levels of SFRP1, SFRP2, SFRP5, DKK2, DKK3, mir34b/c, RASSF1A, IGFBP7, CDKN2A, and MLH1 in isolated cancerous glands and crypts of normal colorectal mucosa adjacent to CRCs. Compared to the surrounding normal colonic crypts, the methylation levels of SFRP1, SFRP2, SFRP5, DKK2, DKK3, mir34b/c, and RASSF1A in microsatellite stable CRCs were 
significantly higher in cancer crypts. These findings confirmed that DNA methylation is thought to potentially be a biomarker for the assessment of cancer risk in normal mucosa (Sugai et al., 2017).

In our study, we used the MSP primers for $D K K 2$ designed in our laboratory and found that the $D K K 2$ gene showed significant differences in its methylation profile between the groups, where the methylation status was more abundant in the CRC group ( $\mathrm{p}<0.001)$. In the case group, most tumors $(84.7 \%$ ) had methylated $D K K 2$ relative to the levels in non-tumor tissues $(11 \%)$, with a sensitivity of tumor detection of $89.1 \%$ and a specificity of $86.8 \%$, giving an accuracy of $87.6 \%$. The methylation of $D K K 2$ did not affect the diseased stage.

Thus, methylation changes are potentially powerful prognostic and predictive markers in colorectal cancer diagnosis and treatment, making it necessary to identify genes that have a differential methylation profile in tumors. New labor and cost-efficient technologies are needed to allow high-throughput assessments of singlelocus methylation changes and the introduction of methylation tests into diagnostic settings.

The National Institute of Health defines a biological marker (biomarker) as a biological molecule found in blood or other body fluids that is an indicator of a normal or abnormal process, a condition, or a disease. A biomarker of cancer can be a molecule secreted by the tumor itself or a specific response of the organism to the presence of the tumor. A biomarker may be associated with the DNA, RNA, miRNA, epigenetic changes, and protein antibody expression (Summers et al., 2013).

Since it has been shown that the methylation of the $D K K 2$ gene is a good indicator for tumor detection, the next step would be the presence of this marker in a biological sample with the objective of assisting in the early detection of tumoral lesions by non-invasive methods. The search for $D K K 2$ methylation marks in plasma is the next step for this study. The circulating free DNA (cfDNA) is derived from cell apoptosis or necrosis and is present in the bloodstream outside of the cell's nucleus. The cfDNA is composed of fragments with an average size of $200 \mathrm{bp}$ and is present at low concentration in plasma (Summers et al., 2013).

Hamakaua et al. demonstrated in gastric cancer samples that concentrations of cfDNA exhibited a good correlation with the disease, as well as the decrease in cfDNA levels after surgical resection, indicating its potential application for the detection of a residual disease. The cfDNA levels were in accordance with CA19-9, CEA markers, and computed tomography, suggesting a comparable ability to monitor the disease's progression (Hamakawa et al., 2015).

\section{CONCLUSION}

Our results introduce the potential of $D K K 2$ as an epigenetic marker for CRC tissues. The PCR-HRM technique proved to be efficient in the detection of methylation marks in the sample studied, presenting a high sensitivity for detection of the epigenetic changes present. A panel of epigenetic markers may be a cost-effective screening tool for CRC and detection of this marker in peripheral blood could be a candidate for a non-invasive biomarker of CRC.

\section{ACKNOWLEDGEMENTS}

This study was supported by the São Paulo Research Foundation (FAPESP)

\section{REFERENCES}

Arnold M, Sierra MS, Laversanne M, Soerjomataram I, et al. (2017). Global patterns and trends in colorectal cancer incidence and mortality. Gut. 66:683-691. https://doi.org/10.1136/gutjn1-2015-310912

Atkin W (2003). Options for screening for colorectal cancer. Scand J Gastroenterol. 237:13-16.

https://doi.org/10.1001/jama.2013.57593

Bernstein BE, Meissner A, Lander ES (2012). The mammalian epigenome. Cell 128:669-681.

https://doi.org/10.1016/j.cell.2007.01.033

Colussi D, Brandi G, Bazzoli F, Ricciardiello L, et al. (2013). Molecular pathways involved in colorectal cancer: implications for

disease behavior and prevention. Int J Mol Sci. 14:16365-85. https://doi.org/10.3390/ijms140816365

Duthie SJ (2011). Epigenetic modifications and human pathologies: cancer and CVD. Proc Nutr Soc. 70:47-56.

https://doi.org/10.1017/s0029665110003952 
Fearon ER, Vogelstein B (1990). A genetic model for colorectal tumorigenesis. Cell. 61:759-67. https://doi.org/10.1016/0092$\underline{8674(90) 90186-\mathrm{i}}$

Frommer M (1992). A genomic sequencing protocol that yields a positive display of 5-methylcytosine residues in individual DNA strands. Proc. Natl. Acad. Sci. USA. 89:1827-1831. https://doi.org/10.1073/pnas.89.5.1827

Gonzalo V, Lozano JJ, Muñoz J, Balaguer F, et al. (2010). Aberrant gene promoter methylation associated with sporadic multiple colorectal cancer. PLoS One 5:8777. https://doi.org/10.1371/journal.pone.0008777

Hamakawa T, Kukita Y, Kurokawa Y, Miyazaki Y, et al. (2015). Monitoring gastric cancer progression with circulating tumour DNA. British Journal of Cancer. 112, 352-356. https://doi.org/10.1038/bjc.2014.609

Hirata H, Hinoda Y, Nakajima K, Kawamoto K, et al. (2009). Wnt antagonist gene DKK2 is epigenetically silenced and inhibits renal cancer progression through apoptotic and cell cycle pathways. Clin Cancer Res. 15:5678-87. https://doi.org/10.1158/1078-0432.ccr$\underline{09-0558}$

Holliday R (1990). Mechanisms for the control of gene activity during development. Biol. Rev. Camb. Philos. Soc. 65:431-471.

ImperialeTF, Ransohoff DF, Itzkowitz SH, Turnbull BA, et al. (2004). Fecal DNA versus fecal occult blood for colorectal cancer screening in an average risk population. N Engl J Med. 351:2704-2714. https://doi.org/10.1056/nejmoa033403

INCA, 2017. http://www.inca.gov.br/estimativa/2017/index.asp?ID=5.

Lansdorp-Vogelaar I, Knudsen AB, Brenner H (2011). Cost-effectiveness of colorectal cancer screening. Epidemiol Rev. 33:88-100. https://doi.org/10.1001/archinte.162.19.2249

Migheli F, Stoccoro A, Coppedè F, Wan Omar WA, et al. (2013). Comparison study of MS-HRM and pyrosequencing techniques for quantification of APC and CDKN2A gene methylation. PLoS One 8: e52501. https://doi.org/10.1371/journal.pone.0052501

Pignone MP, Lewis CL (2009). Using quality improvement techniques to increase colon cancer screening. Am J Med. 122:419-420. https://doi.org/10.1016/j.amjmed.2008.10.029

Siegel RL, Miller KD, Fedewa SA, Ahnen DJ et al. (2017). Colorectal Cancer Statistics, 2017. Ca Cancer J Clin 67:177-193. https://doi.org/10.3322/caac.21395

Silva TD, Vidigal VM, Felipe AV, DE Lima JM, et al. (2013). DNA methylation as an epigenetic biomarker in colorectal cancer. Oncol Lett. 6:1687-1692. https://doi.org/10.3892/ol.2013.1606

Sugai et al. (2017). Analysis of the DNA methylation level of cancer-related genes in colorectal câncer and the surrounding normal mucosa. Clinical Epigenetics. 9:55. https://doi.org/10.1186/s13148-017-0352-4

Summers T, Langan RC, Nissan A, Brücher BL, et al. (2013). Serum-based DNA methylation biomarkers in colorectal cancer: potential for screening and early detection. J Cancer. 4:210-6. https://doi.org/10.7150/jca.5839

Tachibana H, Gotoh O, Wada A (1982). High resolution thermal melting studies of DNA. Prog Clin Biol Res. 64:299-313. Toribara NW, Sleisenger MH (1995). Screening for colorectal cancer. N Eng J Med. 351:861-7.

Voorham QJ, Janssen J, Tijssen M, Snellenberg S, et al. (2013). Promoter methylation of Wnt-antagonists in polypoid and nonpolypoid colorectal adenomas. BMC Cancer. 13:603. https://doi.org/10.1186/1471-2407-13-603

Waddington, C.H (1959). Canalization of development and genetic assimilation of acquired characters. Nature 183:1654-1655. https://doi.org/10.1038/1831654a0

Wang C, Yue Y, Shao B, Qiu Z, et al. (2017). DKK2 Silencing Impairs Wnt/B-Catenin Signaling in Colon Cancer. Cell Physiol Biochem. 41:1709-1724.

Winawer SJ (2007). Colorectal cancer screening. Best Practice and Research Clinical Gastroenterology 21:1031-48.

Wojdacz TK, Borgbo T, Hansen LL (2009). Primer design versus PCR bias in methylation independent PCR amplifications.

Epigenetics 4:231-4. https://doi.org/10.4161/epi.9020

Zhu J, Zhang S, Gu L, Di W (2012). Epigenetic silencing of DKK2 and Wnt signal pathway components in human ovarian carcinoma. Carcinogenesis. 33:2334-43. https://doi.org/10.1093/carcin/bgs278 